\title{
Analysis of the secondary circuit of a gas-cooled fast reactor
}

\author{
Michal Volf ${ }^{*}$, Martin Pelikán ${ }^{1}$, and Pavel Žitek ${ }^{1}$ \\ ${ }^{1}$ University of West Bohemia, Faculty of Mechanical Engineering, Department of Power System \\ Engineering, Univerzitní 22, Pilsen, Czech Republic
}

\begin{abstract}
The article focuses on a power conversion system for a gascooled fast reactor working with helium. The power conversion system, i.e., secondary and possible tertiary system of a power plant, is used to convert heat generated by nuclear fission into electrical energy. The presented research deals with the conceptual design of this system, mainly its secondary circuit, which is assumed to be a Brayton cycle. Several concepts are evaluated, including single and staged compression and possible heat regeneration. The goal of the work is to select the main parameters of such a cycle that would not only be ideal in terms of efficiency, but would also allow decay heat to be used and further converted into electricity. In this way, the secondary cycle could be used as an additional safety system for the nuclear power plant.
\end{abstract}

\section{Introduction}

A power conversion system is a crucial part of any power plant as it converts heat energy into broadly usable electrical energy. It goes without saying that the high efficiency of such a system is the main focus of the design; however, power plant safety is equally important, especially if the plant is a nuclear one. In nuclear power plants, the heat is generated by nuclear fission in different types of reactors and the reactor is cooled down by the secondary cycle during operation under normal operating conditions. This means that the reactor is cooled down using electricity produced by the power plant. However, in an emergency, the turbine (or secondary cycle) is shut down and an additional power supply is needed to cool down the reactor as it still produces some decay heat.

Our focus is aimed at gas-cooled fast reactors (GFR) which are classed as Gen IV reactors, and they feature a closed fuel cycle as well as enhanced safety systems. From a safety point of view, it would be beneficial if in an emergency, the turbine was not shut down, but its operation was extended so that the decay heat produced by the reactor could be further converted to electricity. This electricity could be used to power the reactor's coolant compressors and other components. Thus, the power plant would not need to rely on an external electricity supply or backup power supply to cool down the decay heat of the reactor. Such a system would thus further enhance the safety of the nuclear power plant. [1],

\footnotetext{
* Corresponding author: volfm@kke.zcu.cz
} 
The research presented in this paper is part of a larger project aimed at the conceptual design of an innovative safety system for gas-cooled nuclear reactors. In the article we discuss possible designs of a secondary circuit for a GFR reactor working with helium. The secondary circuit is assumed to be a Brayton cycle with or without staged compression and with or without regeneration. The evaluation is done for different working fluids, namely nitrogen, carbon dioxide and helium, and the possibility of an additional tertiary circuit is discussed. [2], [3]

Bear in mind that the evaluation is done for normal operating conditions, i.e., the state in which the plant works most of the time, and thus needs be designed to have the highest feasible efficiency. The evaluation of secondary circuit behaviour in a power plant emergency (i.e. during reactor shut down) is not presented; however, the secondary circuit is designed with this requirement in mind.

\section{Primary circuit}

The primary circuit of the GFR for which the secondary circuit is analysed, uses helium as the working fluid. The nominal heat power is assumed to be $205 \mathrm{MW}$, mass flow rate is 85 $\mathrm{kg} / \mathrm{s}$ and the output temperature is $850{ }^{\circ} \mathrm{C}$. To cool down the reactor, it is necessary to cool the helium in the heat exchanger to $400{ }^{\circ} \mathrm{C}$. Furthermore, it should be noted that the nominal pressure in the primary circuit is assumed to be $7 \mathrm{MPa}$ and thus, for safety purposes, the pressure in the secondary circuit needs to be higher.

\section{Conceptual design of power conversion system}

\subsection{Overall requirements}

When designing the power conversion system, several aspects must be considered. From the point of utilization of decay heat, it is essential to design the secondary circuit so that it allows the turbine to run for as long as possible. However, considering the entire power plant, the cost plays a significant role and thus the highest efficiency of heat conversion into electricity is desired. Considering nuclear safety, it is obvious that the secondary circuit which should also behave as a safety system must be reliable when operating during reactor shut down. It goes without saying that making priorities between these three diverse requirements is not an easy task and requires thorough consideration. [1], [4]

For the purposes of our research, we consider two principally different approaches to the design of the power conversion system. The first assumes that as much heat as possible will be used in the secondary circuit, even at the cost of the technical complexity of such a cycle. This will lead to a higher cycle efficiency and higher power output of the secondary circuit, leaving the type of tertiary circuit for further consideration as the utilizable heat will be modest.

In the second approach, it is assumed that the simplicity of the secondary cycle is more important for power plant safety in an emergency and reactor shut down since this circuit should behave as a safety system. This means that most of the heat generated by nuclear fission will be converted to electricity in the tertiary circuit, which will likely be a Rankine cycle (i.e., a water steam cycle). This circuit is intended just to increase the overall power plant efficiency and does not play any safety role. 


\subsection{Technical point of view}

Due to the high parameters of pressure and temperature in the primary circuit of a GFR, it is neither safe nor efficient to use a steam cycle (i.e., Rankine cycle) as the secondary circuit of the power plant. The safety risk comes from possible leakage of water into the primary circuit in the heat exchanger which cannot be ruled out, and would result in fatal consequences with severe radiation leakage. Furthermore, the output temperature from the primary circuit is very high and thus for an efficient (i.e. maximum) utilization of heat, the steam cycle would have to be designed as a supercritical one which would further decrease the safety of such a power plant. It goes without saying that this would go against the entire intention of Gen IV reactors as they are designed to excel in safety and reliability. [5]

Therefore, it follows that a three-circuit arrangement will be necessary. Both primary and secondary circuits would be designed as gas cycles, and the tertiary circuit would be either a Rankine cycle or an organic Rankine cycle, depending on the output temperature of the secondary circuit. The choice of gas and tertiary circuit will depend on the results of the optimization.

\section{Secondary circuit arrangement}

For the analysis of the secondary circuit, two principally different arrangements were selected. The first can be seen in Fig. 1 and represents the basic Brayton cycle. In the cycle, a compressor (single or staged) compresses the gas which then enters a heat exchanger (between the primary and secondary circuits) where it heats up by removing heat from the primary circuit. Then, hot compressed gas enters the turbine where its pressure and heat energy is transformed into the mechanical energy of a rotating shaft. After exiting the turbine, the gas is cooled down in a heat exchanger between the secondary and tertiary circuits, meaning that this heat can be further used in the tertiary circuit to generate electricity. If the parameters of this removed heat (especially its temperature) are not sufficient to further generate electrical energy, basic cooling is used instead.

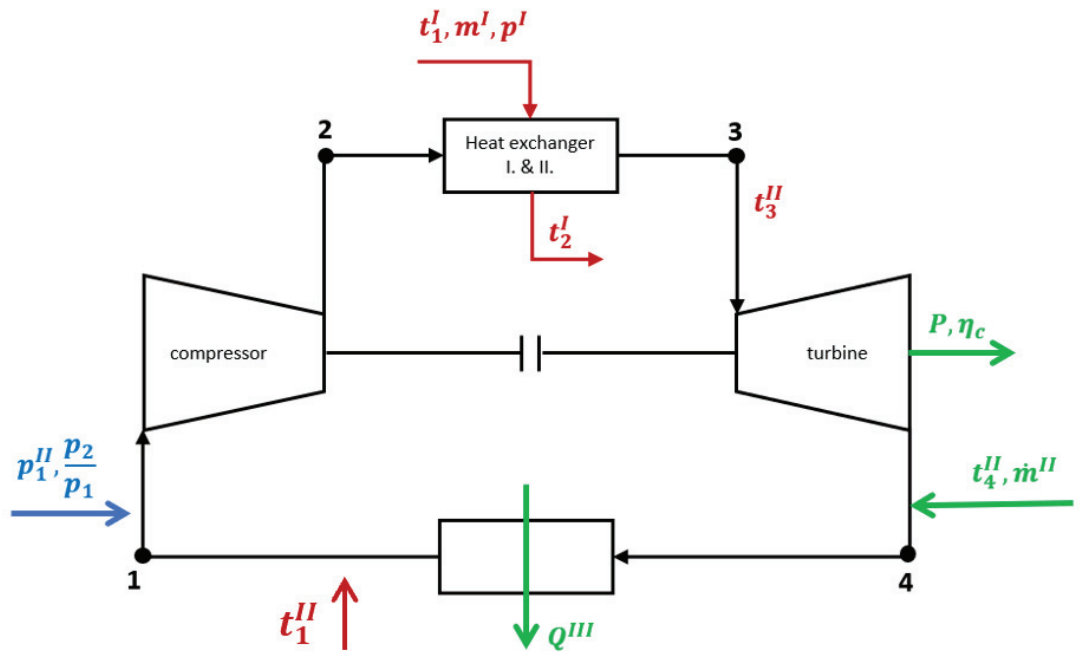

Fig. 1. Secondary circuit without regeneration 
The second arrangement (see Fig. 2) adds a regenerator into the cycle. This means that the compressed gas is preheated before entering the heat exchanger between the primary and secondary cycles. For this, the heat of the gas exiting the turbine is used, which will cause a decrease in the parameters of the heat utilizable for the possible tertiary circuit. On the other hand, the advantage of the regenerator lies in the increase of the cycle efficiency.

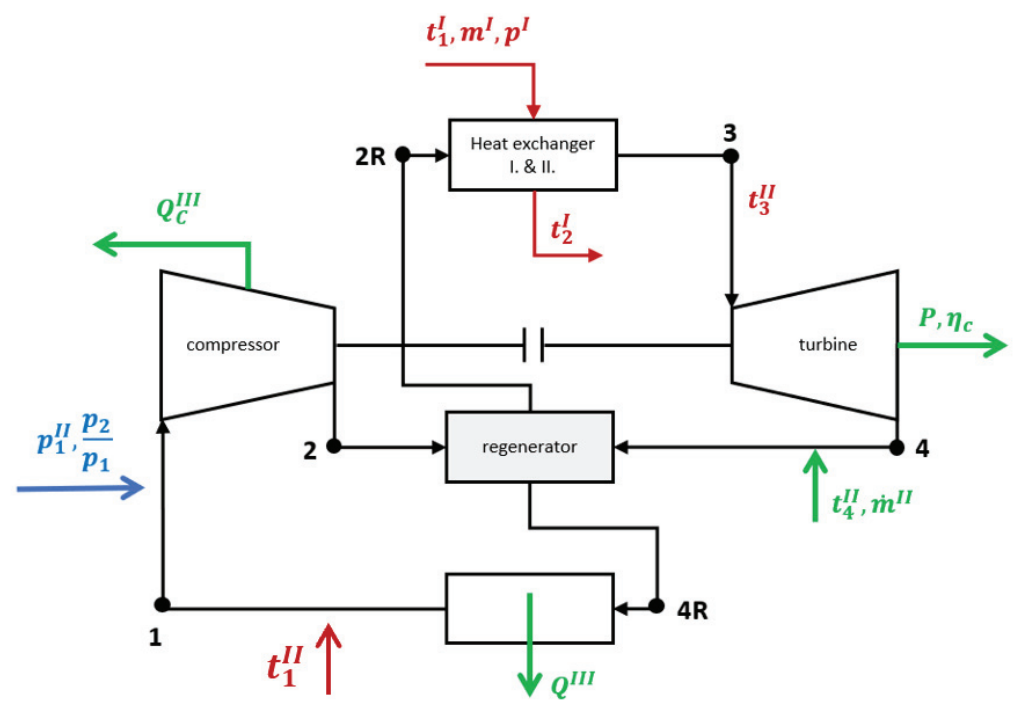

Fig. 2. Secondary circuit with heat regeneration

In both figures above, the evaluated cycle parameters are marked in green, the fixed parameters are marked in red and the varying parameters during the analysis are marked in blue.

\section{Analysis of the secondary circuit}

A script for the balance calculation of the secondary Brayton circuit was developed in MATLAB. It allows us to analyse the main parameters of the circuit for different working gases and various values of the boundary condition, namely the compressor pressure ratio. This in-house script was used to calculate the four variants of the Brayton cycle discussed in the preceding chapter.

For all the analysed cycles, the temperature at the compressor inlet was assumed to be 60 ${ }^{\circ} \mathrm{C}$, and the lowest pressure in the circuit (i.e., the pressure at the compressor inlet) was set to 7.5 $\mathrm{MPa}$ so that it is not lower than the pressure in the primary circuit, which is a safety requirement. Pressure losses as well as turbine and compressor efficiencies were included. The thermodynamic efficiency of the turbine is assumed to be $90 \%$, and for the compressor it is assumed to be $80 \%$. Total pressure losses were estimated to be $600 \mathrm{kPa}$ in total for the heat exchanger regardless of the working gas. We are aware that pressure losses are mainly caused by fluid friction, so for different fluids they could have different values based on viscosity and velocity. Nevertheless, most of the pressure losses occur in the heat exchangers and thus for this initial study, we assume that the heat exchanger would be designed so that the pressure loss would be similar for each fluid.

For the cycles with regeneration, it is assumed that there will be a temperature difference of at least $10^{\circ} \mathrm{C}$, meaning that the temperature at the inlet of the heat exchanger between the primary and secondary circuits (i.e., at the outlet of the regeneration heat exchanger) will not 
exceed $390{ }^{\circ} \mathrm{C}$. For the cycles with staged compression, it is assumed that partially compressed gas will be cooled down in an intermediate heat exchanger to the inlet temperature, and moreover that the compression is ideally divided, meaning the pressure ratios of each stage are equal. It should be noted that only compression divided into two stages is considered.

Firstly, a study to find the optimal pressure ratio at which the highest cycle net efficiency is reached was performed. For each concept, the same varying parameter was used, meaning that the pressure ratio was changed from 1.2 up to 40 . The right boundary is chosen to be this high on purpose so that the optimal pressure ratio lies in the evaluated interval, instead of hitting either the left or the right boundary. It goes without saying that for high values of pressure ratio, the pressure of the compressed gas would be unreasonably and, more importantly, unfeasibly high and thus a second study was performed. This was done assuming a fixed compressor pressure ratio of 3 , which means the pressure of the compressed gas would be $22.5 \mathrm{MPa}$ and thus the realization of such a circuit would still be feasible.

\section{Results of the analysis}

The results of the studies are summarised in Table 1 and Table 2. The column labelled " $p_{2} / p_{1}$ (optimal)" shows the results for the first analysis, i.e., the study to find the pressure ratio for which the cycle would have the highest efficiency. The column labelled " $p_{2} / p_{1}=3$ " presents the results for the fixed pressure ratio of 3, which seems to be the highest reasonably feasible one (in terms of the maximum cycle pressure). For both analyses, the cycle net efficiency $(\eta)$ is shown as well as the cycle net power (P), mass flow rate (m) and output temperature utilizable for the tertiary circuit $(\mathrm{Tm})$.

Table 1. Results of the conceptual study of the secondary circuit ( $\mathrm{p}_{2} / \mathrm{p}_{1}$ (optimal))

\begin{tabular}{|c|c|c|c|c|c|c|c|}
\hline \multirow{2}{*}{ Gas } & \multirow{2}{*}{$\begin{array}{c}\text { Compressor } \\
\text { stages }\end{array}$} & Regeneration & \multicolumn{5}{|c|}{$\mathbf{p}_{2} / \mathbf{p}_{\mathbf{1}}$ (optimal) } \\
\cline { 5 - 8 } & $1^{\circ}$ & no & 7 & 20.6 & 40.0 & 452 & 358 \\
\hline $\mathrm{N}_{2}$ & $\mathbf{p}_{2} / \mathbf{p}_{1}$ & $\begin{array}{c}\mathbf{P} \\
{[\mathbf{M W}]}\end{array}$ & $\begin{array}{c}\mathbf{T}_{\mathbf{I I I}} \\
{\left[{ }^{\circ} \mathbf{C}\right]}\end{array}$ & $\begin{array}{c}\mathbf{m} \\
{[\mathbf{k g} / \mathbf{s}]}\end{array}$ \\
\hline $\mathrm{N}_{2}$ & $1^{\circ}$ & yes & 4.8 & 23.0 & 44.8 & 423 & 376 \\
\hline $\mathrm{N}_{2}$ & $2^{\circ}$ & no & 9.8 & 22.3 & 43.5 & 400 & 267 \\
\hline $\mathrm{N}_{2}$ & $2^{\circ}$ & yes & 7.8 & 31.3 & 61.0 & 233 & 371 \\
\hline $\mathrm{He}$ & $1^{\circ}$ & no & 4 & 18.8 & 36.6 & 432 & 82 \\
\hline $\mathrm{He}$ & $1^{\circ}$ & yes & 3.2 & 21.1 & 41.0 & 406 & 85 \\
\hline $\mathrm{He}$ & $2^{\circ}$ & no & 5.4 & 21.0 & 40.9 & 365 & 63 \\
\hline $\mathrm{He}$ & $2^{\circ}$ & yes & 4.4 & 29.3 & 57.0 & 226 & 85 \\
\hline $\mathrm{CO}_{2}$ & $1^{\circ}$ & no & 19.4 & 26.3 & 51.3 & 449 & 312 \\
\hline $\mathrm{CO}_{2}$ & $1^{\circ}$ & yes & 10.6 & 29.7 & 57.8 & 411 & 329 \\
\hline $\mathrm{CO}_{2}$ & $2^{\circ}$ & no & 24.4 & 25.1 & 48.9 & 425 & 207 \\
\hline $\mathrm{CO}_{2}$ & $2^{\circ}$ & yes & 15.4 & 39.7 & 77.2 & 147 & 324 \\
\hline
\end{tabular}


Table 2. Results of the conceptual study of the secondary circuit $\left(\mathrm{p}_{2} / \mathrm{p}_{1}=3\right)$

\begin{tabular}{|c|c|c|c|c|c|c|}
\hline \multirow{2}{*}{ Gas } & \multirow{2}{*}{$\begin{array}{c}\text { Compressor } \\
\text { stages }\end{array}$} & \multirow{2}{*}{ Regeneration } & \multicolumn{4}{|c|}{$\mathbf{P}_{2} / \mathbf{p}_{\mathbf{1}}=\mathbf{3}$} \\
\cline { 5 - 7 } & & $\begin{array}{c}\mathbf{7} \\
{[\%]}\end{array}$ & $\begin{array}{c}\mathbf{P} \\
{[\mathbf{M W}]}\end{array}$ & $\begin{array}{c}\mathbf{T}_{\text {III }} \\
{\left[{ }^{\circ} \mathbf{C}\right]}\end{array}$ & $\begin{array}{c}\mathbf{m} \\
{[\mathbf{k g} / \mathbf{s}]}\end{array}$ \\
\hline $\mathrm{N}_{2}$ & $1^{\circ}$ & no & 14.4 & 28.1 & 608 & 274 \\
\hline $\mathrm{N}_{2}$ & $1^{\circ}$ & yes & 20.0 & 38.9 & 433 & 379 \\
\hline $\mathrm{N}_{2}$ & $2^{\circ}$ & no & 14.4 & 28.1 & 608 & 241 \\
\hline $\mathrm{N}_{2}$ & $2^{\circ}$ & yes & 22.7 & 44.2 & 346 & 379 \\
\hline $\mathrm{He}$ & $1^{\circ}$ & no & 17.1 & 33.4 & 506 & 70 \\
\hline $\mathrm{He}$ & $1^{\circ}$ & yes & 21.0 & 40.9 & 407 & 85 \\
\hline $\mathrm{He}$ & $2^{\circ}$ & no & 17.5 & 34.0 & 506 & 56 \\
\hline $\mathrm{He}$ & $2^{\circ}$ & yes & 26.5 & 51.5 & 280 & 85 \\
\hline $\mathrm{CO}_{2}$ & $1^{\circ}$ & no & 12.6 & 24.5 & 686 & 228 \\
\hline $\mathrm{CO}_{2}$ & $1^{\circ}$ & yes & 19.4 & 37.8 & 437 & 352 \\
\hline $\mathrm{CO}_{2}$ & $2^{\circ}$ & no & 12.5 & 24.3 & 686 & 195 \\
\hline $\mathrm{CO}_{2}$ & $2^{\circ}$ & yes & 22.5 & 43.8 & 311 & 352 \\
\hline
\end{tabular}

\subsection{Analysis of the optimal pressure ratio}

At first glance the results show very good efficiencies of the Brayton cycle, reaching values of over $30 \%$ (nitrogen with staged compression, including regeneration). However, taking closer look, it can be seen that for all configurations, the optimal compressor pressure ratios are far too high and thus the maximum pressure in the cycle would reach extreme values. Assuming the feasible pressure ratio is up to the value of 3 (the corresponding maximum pressure in the cycle is $22.5 \mathrm{MPa}$ ), only the cycle with helium approaches this, as the optimal pressure ratio for single compression and regeneration is 3.2. Nevertheless, due to the low molar mass of helium, real-life pressure ratios for which the compressor can be designed are even lower. All in all, it can be concluded that it is not likely to use the full potential of the cycle, so the tertiary cycle is necessary to improve the overall power plant efficiency and use as much heat generated by nuclear fission as possible.

\subsection{Analysis for the fixed compressor pressure ratio of 3}

Looking at the efficiencies, it can be seen that the highest efficiency would be for a secondary circuit with helium and both staged compression and regeneration. However, the temperature of the residual heat for the tertiary cycle $\left(280^{\circ} \mathrm{C}\right)$ is not sufficient for the subsequent Rankine tertiary circuit and thus a further increase of the power plant efficiency seems to be considerably limited. From this point of view, it seems to be more convenient to use a secondary circuit working with either nitrogen or carbon dioxide, since both allow for a common Rankine tertiary cycle. Furthermore, it should be added that since helium is a very light gas, reaching a pressure ratio of 3 would require a large compressor (many axial stages if an axial one is used) and thus the real-life pressure ratio would need to be lower. It follows 
that for lower pressure ratios, the efficiency would further decrease (assuming all the other parameters remain the same), which makes the cycle with helium an unviable choice to proceed with.

The cycle with carbon dioxide seems to reach quite high efficiency values for both single and staged compression if regeneration is applied. The single compression would make the circuit simpler from a technical point of view which is convenient for the safety purposes discussed at the beginning of the article. Nevertheless, carbon dioxide is not chemically stable at temperatures above $633^{\circ} \mathrm{C}[6]$ so using it would create further issues.

Considering all these factors, a Brayton secondary circuit with nitrogen and without staged compression seems to be the ideal choice, since it allows for a proper Rankine tertiary circuit that would significantly increase the overall power plant efficiency. Furthermore, the properties of nitrogen are very similar to the properties of air and so, unlike for helium, there would be no issues regarding chemical stability or gas leakage. Finally, this cycle configuration is also technically simple and thus it fits the safety approach in the design of the power conversion system. The T-s and h-s diagrams for this cycle (without regeneration) are shown in Fig. 3. Regeneration could be used in the secondary circuit to increase its efficiency; however, it would decrease the utilizable temperature for the tertiary circuit. Therefore, the decision whether or not to regenerate heat should be made based on an advanced analysis including the tertiary circuit, which is planned in the later stages of our project. Nevertheless, the parameters of the compressors and turbine remain the same.
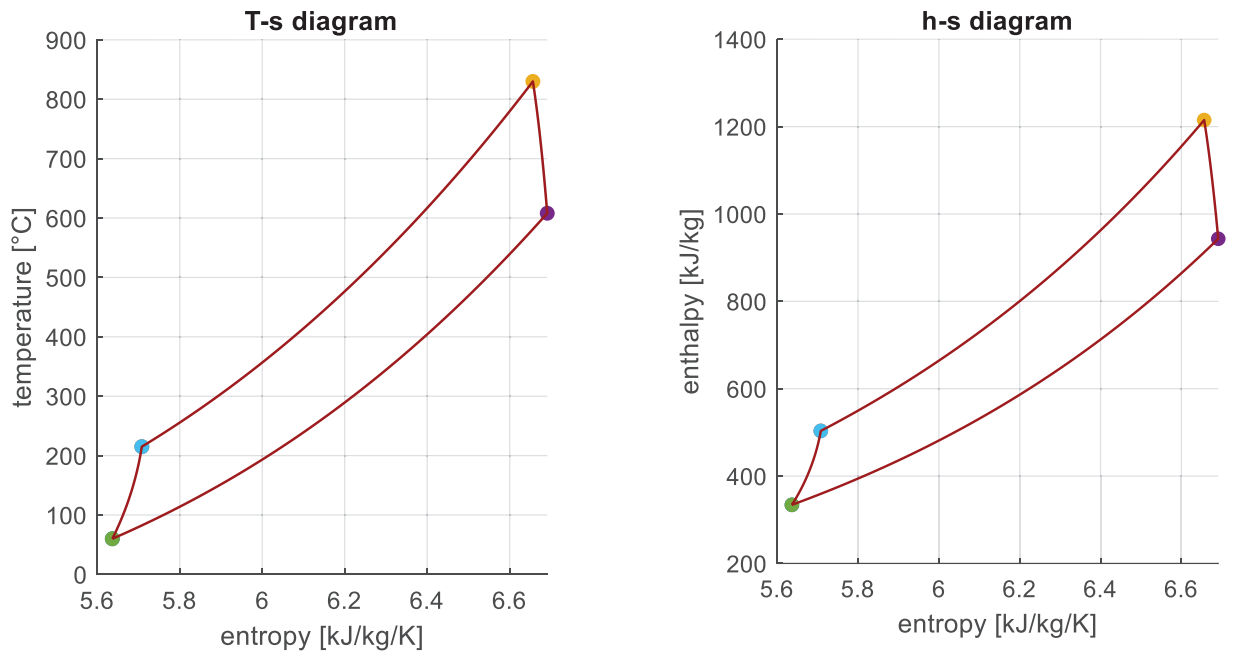

Fig. 3. T-s and h-s diagrams of the selected secondary circuit (compressor inlet: $60{ }^{\circ} \mathrm{C}, 7.5 \mathrm{MPa}$; compressor outlet: $215{ }^{\circ} \mathrm{C}, 22.5 \mathrm{MPa}$; turbine inlet: $830{ }^{\circ} \mathrm{C}, 21.9 \mathrm{MPa}$; turbine outlet: $608.1{ }^{\circ} \mathrm{C}$, $8.1 \mathrm{MPa})$

\section{Conclusion}

In the article, the initial study of a power conversion system for a gas-cooled fast reactor was presented. The goal of the power conversion system is not just to convert heat into electrical energy but also to behave as a safety system in an emergency and reactor shut down. Several configurations of a secondary circuit were analysed to find the ideal pressure ratio at which the net cycle efficiency would be the highest. However, based on the results, the ideal ratios were too high to be considered feasible and thus a second analysis was done assuming a fixed 
pressure ratio of 3 . This analysis showed that the secondary circuit should use nitrogen as a working fluid and should have a single compression to achieve a technically simpler cycle. The decision of whether to utilize heat regeneration within the cycle was not made as this should be based on a subsequent larger analysis that will include the tertiary circuit.

This project is co-financed from the state budget by the Technology Agency of the Czech Republic under the THETA Programme, project number TK03030121 - Conceptual Design of an Innovative Safety System for Gas-cooled Nuclear Reactors. The presented work was also financially supported by student project SGS-2019-021 (Improving the efficiency, reliability and service life of power machines and equipment 5).

\section{References}

1. Gas cooled fast reactor research in Europe. Stainsby, Richard, et al. 9, s.1. : Nuclear Engineering and Design, 2011, Vol. 241. ISSN 0029-5493.

2. Analysis of a 115MW, 3-Shaft, Helium Brayton Cycle Using Nuclear Heat Source. Kumar, Pradeep K, Tourlidakis, A and Pilidis, P. New Orleans, Louisiana : ASME, 2001. V002T04A028.

3. Thermodynamic analysis and preliminary design of closed Brayton cycle using nitrogen as working fluid and coupled to small modular Sodium-cooled fast reactor (SM-SFR). Olumayegun, Olumide, Wang, Meihong and Kelsall, Greg. s.l. : Applied Energy, 2017, Vol. 191, pp. 436-453. ISSN 0306-2619.

4. The Supercritical Carbon Dioxide Power Cycle: Comparison to Other Advanced Power Cycles. Dostal, Vaclav, Hejzlar, Pavel and Driscoll, Michael J. s.1. : Nuclear Technology, 2006, pp. 283-301.

5. Generation IV nuclear reactors: Current status and future prospects. Locatelli, Giorgio, Mancini, Mauro and Todeschini, Nicola. s.1. : Energy Policy, 2013, Vol. 61. ISSN 0301-4215.

6. The thermal decomposition of carbon dioxide. M.H. Lietzke, Chantal Mullins. 1981, Journal of Inorganic and Nuclear Chemistry, pp. 1769-1771. 